\title{
MECHANISMS IN ENDOCRINOLOGY Hypophysitis: diagnosis and treatment
}

\author{
Mamta N Joshi', Benjamin C Whitelaw ${ }^{2,3}$ and Paul V Carroll ${ }^{1,3}$ \\ 'Department of Endocrinology, Guy's \& St. Thomas' NHS Foundation Trust, London, UK, Department of \\ Endocrinology, Kings College Hospital NHS Foundation Trust, London, UK, and ${ }^{3}$ Faculty of Life Sciences \& Medicine, \\ King's College Hospital London, London, UK
}

Correspondence should be addressed to P V Carroll

Email

paul.carroll@gstt.nhs.uk

\begin{abstract}
Hypophysitis is a rare condition characterised by inflammation of the pituitary gland, usually resulting in hypopituitarism and pituitary enlargement. Pituitary inflammation can occur as a primary hypophysitis (most commonly lymphocytic, granulomatous or xanthomatous disease) or as secondary hypophysitis (as a result of systemic diseases, immunotherapy or alternative sella-based pathologies). Hypophysitis can be classified using anatomical, histopathological and aetiological criteria. Non-invasive diagnosis of hypophysitis remains elusive, and the use of currently available serum anti-pituitary antibodies are limited by low sensitivity and specificity. Newer serum markers such as anti-rabphilin 3A are yet to show consistent diagnostic value and are not yet commercially available. Traditionally considered a very rare condition, the recent recognition of IgG4-related disease and hypophysitis as a consequence of use of immune modulatory therapy has resulted in increased understanding of the pathophysiology of hypophysitis. Modern imaging techniques, histological classification and immune profiling are improving the accuracy of the diagnosis of the patient with hypophysitis. The objective of this review is to bring readers up-todate with current understanding of conditions presenting as hypophysitis, focussing on recent advances and areas for future development. We describe the presenting features, investigation and diagnostic approach of the patient with likely hypophysitis, including existing conventional techniques and those in the research/development arena. Hypophysitis usually results in acute and persistent pituitary hormone deficiency requiring long-term replacement. Management of hypophysitis includes control of the inflammatory pituitary mass using a variety of treatment strategies including surgery and medical therapy. Glucocorticoids remain the mainstay of medical treatment but other immunosuppressive agents (e.g. azathioprine, rituximab) show benefit in some cases, but there is a need for controlled studies to inform practice.

\section{Invited Author's profile}

Paul Carroll is the Clinical Lead for Endocrinology at Guy's and St Thomas' NHS Foundation Trust and Honorary Senior Lecturer at Kings College London. He qualified from Trinity College Dublinand trained in Endocrinology at St. Bartholomew's and St. Thomas' Hospitals in London developing particular interests in pituitary, adrenal and thyroid disease. His research interests include clinical aspects of pituitary disease and inherited endocrine conditions.

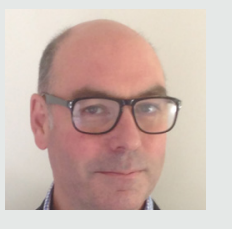

(c) 2018 European Society of Endocrinology Printed in Great Britain
Published by Bioscientifica Ltd. 


\section{Introduction}

Hypophysitis is the collective term for conditions presenting with inflammation of the pituitary gland and infundibulum. Hypophysitis can occur as a primary entity or secondary to a predisposing local sella or multi-systemic inflammatory conditions. Hypophysitis is a rare condition; however, the recent recognition of IgG4-related disease (IgG4-RD) and the introduction of immune checkpoint inhibitors, as cancer therapies with endocrine adverse effects has prompted increased interest in inflammatory disorders affecting the pituitary gland. In the existing literature, the term hypophysitis has been used to describe a number of conditions that present with either primary or secondary inflammation of the pituitary gland. There has been inconsistency in the classification and commonly overlap in using the term for both inflammatory and neoplastic processes (including Langerhan's cell histiocytosis (LCH)). This highlights the potentially broad differential that must be considered in the patient presenting with clinical and investigative features consistent with hypophysitis. This review guides the reader through the classification systems and highlights the diagnostic strategy. Recently recognised and emerging forms of hypophysitis are discussed in detail.

Hypopituitarism related to infective conditions has been documented for over a century (1), but it is only in the last 50 years that we have been able to begin to evaluate the primary pathologies leading to hypophysitis (2). Histological description of some of the originally described case reports suggests that lymphocytic infiltration of the gland was noted as early as the beginning of the last century (1), and in the 1950s, this was identified to have an autoimmune association (3). Our understanding of hypophysitis has grown considerably in the last decade, with contributions from large case series and comprehensive review articles $(4,5,6)$.

The overall prevalence of these diseases remains low and hypophysitis is still considered a rare condition. Population-based studies report an incidence of hypophysitis (all types combined) to be about 1 in 9 million (4), but this is an underestimate, particularly as IgG4-related disease and involvement of the hypophysis by systemic pathologies has increasingly been recognised. Neurosurgical centres report hypophysitis prevalence to be of $<1 \%$ of sella and suprasella lesions referred for evaluation $(0.24-0.88 \%(4,7))$.

This review summarises the current literature on the diagnosis and management of hypophysitis, with emphasis on discussion of the newer and less common clinical entities such as immune checkpoint therapy-related hypophysitis and IgG4 hypophysitis. Little is known about the optimal diagnostic approach and treatment of both primary and secondary hypophysitis and we have summarised the available literature. We have also included areas of future research and future anticipated clinical developments. The review provides guidance for the clinician investigating and managing patients presenting with hypophysitis.

\section{Data collection}

We performed a PubMed-based search of articles using the search terms hypophysitis, adenohypophysitisadenohypoph, infundibulohypophysitis, autoimmune infection IgG4 granulomatous xanthomatous autoimmune, infection, IgG4, granulomatous, xanthomatous, immune checkpoint, CTLA-4, PD1, PD-L1 and combined them with hypophysitis, hypopituitarism, pituitary. After the original search, we used filters to select articles available in English, articles with available full texts and removed duplicate articles resulting in 1074 articles. Further shortlisting was done based on the relevance of the titles using filtering for mesh terms or text-words. The final search derived 271 articles. Of these, 53 articles were review articles, 169 were case reports and 49 were other journal articles.

\section{Classification of hypophysitis}

In clinical practice, the term hypophysitis is used as an umbrella encompassing the conditions that present as a result of either primary or secondary pituitary hypophysitis. A number of classification systems have evolved to categorise hypophysitis. These include using aetiology, pattern of pituitary involvement and histological findings. In many patients, histological confirmation of the pathology has not been possible. Therefore, using a solely histology-based classification mechanism has not been possible for all patients. It is conventional to classify based on aetiology (or presumed aetiology); with conditions described as either primary (affecting the hypothalamo-pituitary structures) or secondary hypophysitis. The commonest primary condition is lymphocytic hypophysitis with idiopathic granulomatous hypophysitis being less common. Secondary causes include autoimmune conditions (e.g. systemic lupus erythematosus, autoimmune polyglandular syndrome). Traditionally infiltrative conditions including $\mathrm{LCH}$ and 
sarcoidosis have been included in the hypophysitis category. Drug therapy-induced hypophysitis, especially with CTLA-4 inhibitors, is a new entity increasingly recognised by oncologists and endocrinologists.

Historically, hypophysitis has also been just classified according to the pattern of the hypothalamic, pituitary and pituitary stalk (PS) involvement. This approach is limited as it does not necessarily relate to the particular aetiology but does have implications for describing the associated pituitary hormone deficits that arise. Patients with involvement of the neurohypophysis and those with pan-hypophysitis typically present with diabetes insipidus related to ADH deficiency. Those with pure involvement of the anterior pituitary do not have diabetes insipidus but present with the consequences of anterior pituitary hormone deficiency.

Hypophysitis can also be classified using histological appearances. Biopsy is most commonly performed to distinguish between neoplastic and inflammatory conditions and ideally make a categorical diagnosis. When a successful biopsy has been achieved, this approach is useful in guiding management decision making. There is overlap in the presentation of granulomatous, lymphocytic and xanthomatous lesions and making clear distinction between these entities is not always possible. Existing reports are mostly retrospective and are limited by lack of diagnostic histopathology. The classification of primary hypophysitis and secondary predisposing factors are summarised in Tables 1 and 2.

\section{Clinical presentation of hypophysitis}

Pituitary inflammation (either primary or secondary) usually results in pituitary hormone deficiency and enlargement of the pituitary gland. Inflammatory or infiltrative expansion of the pituitary gland can result in compression of the optic apparatus with resulting neuroophthalmic consequences. These usually include visual field defects but reduction in colour perception and visual acuity can also occur. Involvement of the cavernous sinus with ophthalmoplegia is rare but described (8). Headache is a consistently reported symptom in the patient with hypophysitis.

Endocrine manifestations include anterior pituitary hormone deficiencies, diabetes insipidus and abnormal serum prolactin (either hypo or hyperprolactinaemia (6). The pattern of endocrine dysfunction maybe influenced by the aetiology. Lymphocytic hypophysitis is considered to have a predilection to ACTH, gonadotrophin, TSH, GH deficiencies
Table 1 Classification of primary hypophysitis (adapted and modified from(91)).

(a) Based on anatomy Lymphocytic adenohypophysitis Lymphocytic infundibuloneurohypophysitis Lymphocytic pan-hypophysitis

(b) Based on histology Lymphocytic hypophysitis Granulomatous hypophysitis Xanthomatous hypophysitis Plasmacytic/lgG4-related hypophysitis Necrotising hypophysitis Mixed forms (lymphogranulomatous, xanthogranulomatous)

in this sequence, but isolated hormone deficiencies though rare, have been reported $(4,9)$. The pattern of hormone deficits may differ in IgG4-RD and immune checkpoint inhibitor-related hypophysitis. It has been suggested that hyperprolactinemia is a feature predominantly seen in the acute phase of the lymphocytic hypophysitis, and simultaneously, other symptoms of pituitary enlargement may be present (5). Involvement of PS in isolation (infundibulo-hypophysitis) and entire involvement of the pituitary gland and stalk (pan-hypophysitis) are more likely to present with diabetes insipidus (the latter including anterior pituitary hormone deficiency).

Headache with or without nausea, vomiting ( $>50 \%)$ and visual disturbances are common, as described in large case studies $(6,10)$. Cranial nerve palsies $(10,11)$, cavernous sinus involvement (10), intracavernous carotid

Table 2 Conditions predisposing to the development of hypophysitis.

Autoimmune conditions

- Systemic lupus erythematosus (SLE)

- Autoimmune polyglandular syndrome (APS)

Systemic inflammatory disorders

- Sarcoidosis

- Granulomatosis with polyangitis

- IgG4-disease

- Other granulomatous (Crohn's, Takayasu's, Castlemans' disease)

Drug induced

- Immune checkpoint therapy (CTLA4 Ab, PD-1 Ab)

- Interferon $\alpha$

Infiltrative lesions

- Langerhans cell histiocytosis

- Erdheim-Chester disease

Local tumour effect (Sellar diseases)

- Rupture of Rathke's cleft cyst

- Germinoma

Infection

- Tuberculosis

- Syphilis

- Fungal infections 
artery occlusion (12), meningitis-mimic (13) and even apoplexy-mimic $(11,14)$ presentations have been reported. Amongst the other common non-endocrine symptoms reported in a recent German study include weight gain and features of associated autoimmune conditions (10).

The relationship to pregnancy and known existing conditions and their treatments are important to identify the aetiology of hypophysitis. A relationship with pregnancy (particularly third trimester or early post-partum) provides evidence to support a diagnosis of lymphocytic hypophysitis.

Given the possibility that hypophysitis may be secondary to a systemic condition or an infiltrative disorder, it is important to consider a broad history and examination. Conditions such as sarcoidosis or LCH might manifest with symptoms of respiratory or bone disease. Drug history may be relevant, especially when newer oncology medications are used as immune therapy. Immune checkpoint inhibitors, most commonly ipilimumab, result in hypophysitis and thyroiditis as recognised adverse effects. A large case series of 152 PS lesions reported neoplastic lesions (32\%) were more common than inflammatory pathologies (20\%), highlighting the relevance of a broad differential (15).

\section{Investigation of the patient with hypophysitis}

1. Biochemistry

2. A full early morning pituitary-related hormonal profile including cortisol, ACTH, IGF-1, GH, oestradiol (pre-menopausal females)/testosterone, LH, FSH, free thyroxine, TSH, prolactin, plasma/urine osmolality, electrolytes should be a part of the hormonal work up. Biochemical evaluation of the gonadotrophin axis may not be indicated in a pre-menopausal female with normal menstruation. In patients with suspected diabetes insipidus, levels of anti-diuretic hormone should be measured, where feasible. Routine baseline investigations such as full blood count, peripheral smear, renal, liver and bone profile, C-reactive protein (CRP), erythrocyte sedimentation rate (ESR) can provide subtle clues to the nature of the systemic process. Based on the clinical suspicion or differential diagnosis, further biochemical and radiological investigations can be considered, as summarised in Table 3.

\section{Radiology}

4. Gadolinium-enhanced pituitary MRI is considered as the preferred radiologic investigation of choice to define pituitary anatomy and appearances. The radiological features suggestive of hypophysitis include a prompt, intense and homogenously enhancing gland with no obvious stalk deviation. This is further supported by the absence of posterior pituitary bright spot, particularly, in patients presenting with diabetes insipidus. The lesions are commonly associated with symmetrical suprasella extension and enhancement of the adjacent dura referred as 'dural tail' (16). These features are most prominent in the patient with classical lymphocytic hypophysitis. IgG4 hypophysitis and immune checkpoint therapy-related hypophysitis

Table 3 Investigations for suspected hypophysitis (excluding histology).

\section{Suspected conditions}

Lymphocytic hypophysitis

Granulomatous lesions

IgG4-related disease

Langerhan cell histiocytosis (LCH)/Erdheim-Chester disease (EDH)

Germinoma (if considered as differential to hypophysitis)

Other infiltrative/infectious aetiologies

\section{Investigations}

Thyroid antibodies (TPO)

Anti-nuclear antibody

Anti-Ro, anti-La, anti-SSa, anti-Ds-DNA (if concomitant autoimmune features present)

Pituitary antibody

Chest X-ray, interferon gamma assay if history of travel and tuberculosis suspected

Serum ACE levels if sarcoidosis suspected

ANCA antibodies

CSF analysis for glucose, protein, oligoclonal bands, ACE

CT and scintigraphy

Immunoglobulin levels, particularly IgG4

FDG PET for disease activity

Skeletal survey, whole body bone scan

FDG PET for disease activity

Serum and CSF AFP (alpha-fetoprotein) and HCG (human chorionic gonadotropin)

LDH (lactic acid dehydrogenase), urine analysis Imaging

CSF analysis (cytology, oligoclonal bands) 
have not been reported to have unique or distinctive radiological characteristics that facilitate clear categorisation. The characterisation of the unusual sellabased mass is not straightforward and generally results in a wide differential. Not uncommonly, the presence of an 'empty sella' has been considered as the atrophic response of the burnt out inflammatory process (17). To aid distinction between pituitary adenoma and hypophysitis, Gutenberg et al. derived a radiologic scoring system (18). They used relation to pregnancy, pituitary mass volume and symmetry, signal intensity and signal intensity homogeneity after gadolinium administration, posterior pituitary bright spot presence, stalk size and mucosal swelling for the calculation of the score (18). The score ranges from -13 to +8 and a score of $\geq 1$ was suggestive of adenoma, whereas a score of $\leq 0$ suggested hypophysitis. Despite the systematic scoring, the differentiation continues to remain difficult (5). In a recent systematic review, Catford et al. demonstrated that isolated PS lesions are more common in LCH, lymphocytic hypophysitis, germ cell tumours or metastases, but imaging in isolation does not differentiate between aetiologies (20).

5. If surveillance is the preferred initial management, then follow-up with 3-6 monthly or annual scans are used. A closer follow-up may be preferred when a suspected malignant lesion has not been ruled out. A significant proportion of lesions will progress. Jian et al. demonstrated changes to baseline images in 21 out of 37 PS lesions over a mean follow-up of 4.2 years (19). They recommended using progression of stalk thickness as a guide to consider pituitary biopsy.

6. In patients suspected to have secondary hypophysitis related to systemic pathology, additional imaging is helpful to identify other involved sites of disease. CT chest, abdomen and pelvis is useful in patients with potential sarcoidosis, $\mathrm{TB}$, connective tissue disorders or when malignancy is a potential differential diagnosis. The introduction of FDG PET-CT has been helpful in confirming multisite disease and avoiding the need for pituitary biopsy in patients with IgG4related disease and LCH $(20,21)$.

\section{Immunology}

8. Attempts to consistently identify autoantigens that can be implicated in the causation of hypophysitis have been unsuccessful $(6,9)$. Numerous researchers over the years have reported presence of possible antigens such as alpha enolase (22), secretogranin II (23), chromosome 14 open reading frame 166 (24), pituitary gland-specific factors (PGSF1a and PGSF2
(25) and pituitary-specific transcriptional factor 1 (26), but the pathogenicity of these antigens has not been confirmed. One study demonstrated antirabphilin-3A antibody in 76\% (22/29) patients with central DI and suspected lymphocytic infundibular neurohypophysitis, suggesting a potential role as a future diagnostic biomarker (27).

9. Serum anti-pituitary antibodies have a low sensitivity and specificity and therefore are normally thought to be of limited use. Ricciuti et al. reviewed 122 articles using immunofluorescence-based testing methods and provided helpful guidance in the identification of pituitary antibodies (28). However Bellastella et al. recently suggested that looking for anti-pituitary antibodies may be helpful in selective situations such as patients with apparently idiopathic hypopituitarism with other autoimmune diseases, in patients with hyperprolactinemia without pituitary adenoma at MRI, without hypothyroidism or associated with iatrogenic causes or in patients with empty sella (5). Furthermore, in select cases, anti-hypothalamus antibodies may help to establish association of the presenting condition with a selective hypothalamic or pituitary autoimmune process (5). These tests are not currently part of routine practice. Other diseasespecific antibodies (such as ANA, ds-DNA, ANCA) may be useful in the assessment of secondary hypophysitis.

10. Data from the Hopkins Hypophysitis Registry suggest that demonstrable co-existing autoimmune pathology in the patient with hypophysitis is uncommon with autoimmune thyroid disease (the commonest co-associate) present in only $8 \%$ of patients with autoimmune hypophysitis (4).

\section{Histology}

12. Histological assessment will provide confirmation and classification of hypophysitis and therefore is the most robust and definitive method of diagnosis. However, obtaining histology will require neurosurgical biopsy or resection of sella or suprasella tissue, and this potentially involves significant morbidity. Obtaining a tissue sample might also not be practical for other reasons, including spontaneous resolution or regression, response to initial medical management such as steroid therapy or difficulty in obtaining patient consent.

13. When available, evaluation of the histological specimen provides valuable information about the nature of the disease. Histologic stains to identify inflammatory cells and use of tissue (such as CD45 (leukocyte common antigen), CD3 (T-cells), CD20 
(B cells), CD68 (macrophages) and CD138 (plasma cells)) and hormone-specific immune staining helps to delineate different types of hypophysitis (29). The presence of histiocytes, granulomas xanthomas are essential to confirm specific subtypes of pituitary inflammatory lesions.

\section{Treatment of hypophysitis}

The natural history of hypophysitis is variable, and there is no strong evidence base for management recommendations. It is likely that increased understanding of the specific causal conditions and their treatment responses (e.g. IgG4-related disease, immune checkpoint inhibitor treatment) will emerge with future studies. Bellastella et al. distinguish between the acute phase of hypophysitis, which may require primary treatment; and a chronic or burnt out phase during which only treatment of hypopituitarism is needed (7). Hypopituitarism and diabetes insipidus should be treated according to conventional recommendations (30).

The main objectives of treatment are to manage pituitary hormone deficiencies and to reduce the inflammatory pituitary enlargement with associated mass-related consequences. Primary treatment of the hypophysitis falls into four categories which include: surgery, anti-inflammatory medical therapy, conservative management and radiotherapy. Historically, surgery remains the preferred method of choice (4) when there is significant mass effect. The advantages of surgery are that it provides a histological diagnosis to guide future management and excludes the diagnosis of tumour. It also reliably and quickly treats mass effects and visual impairment due to the lesion (31). In a large German cohort, surgery for hypophysitis resulted in significant resolution of symptoms such as headaches and visual disturbances $(31,32,33)$. The rate of recurrence of the lesion after surgery was reported to be $11-25 \%(31,32)$. Post-operative follow-up showed the development of pituitary insufficiencies and was particularly frequent after gross total resection compared to biopsy or partial resection.

There are limited reports of spontaneous resolution of hypophysitis. In cases without significant mass effect or headache, surveillance of hypophysitis can be used in addition to replacement of endocrine insufficiencies $(31,34)$.

Glucocorticoid therapy forms the cornerstone of medical management. Numerous authors have confirmed an initial good response to 'steroid therapy', but the overall recurrence rate has been reported to be high and highlights the limitations of this treatment $(33,35)$. Up to $38 \%$ patients developed relapse on steroid therapy, in a recent large cohort (31). As is expected, treatment with long-term steroids leads to increasing adverse effects and limits the use of this strategy (31). In cases with progressive or recurrent disease steroid-sparing options such as alternative immune-suppressive agents or radiotherapy have been considered. A variety of agents have been used, and experience often reported as case reports. Supplementary Table 4 (see section on supplementary data given at the end of this article) provides a brief summary of the papers reporting use of steroid-sparing therapies. The last few years have seen a rise in the use of immunosuppressive therapies for resistant lesions (36). Azathioprine is the most commonly used immunesuppressive agent at present, while in the coming years, it is likely we will see more focussed monoclonal antibodydirected therapy such as rituximab (31).

Hyperprolactinaemia affects a minority of cases in the acute phase of the pituitary inflammation (5). Some authors have reported the possibility of prolactin modulating autoimmunity and the use of dopamine agonists for inducing treatment response $(37,38)$. While the beneficial effect of long-term dopamine agonist treatment is still uncertain (5), the use of cabergoline/ bromocriptine in hyperprolactinaemic patients is likely to provide symptomatic relief (from galactorrhoea and/or hypogonadism if present). The approach to managing the patient with suspected hypophysitis is outlined in Fig. 1.

\section{Specific conditions causing hypophysitis}

\section{Lymphocytic hypophysitis}

2. Lymphocytic hypophysitis (LH, autoimmune hypophysitis) is a rare inflammatory/autoimmune disease that involves the pituitary gland and stalk (1). The clinical features include headache, variable degrees of hypopituitarism and frequently diabetes insipidus. Mass effect with visual consequence may be present. Both genders and all ages may be affected but the condition is classically identified during pregnancy or early post-partum (2). The diagnosis is confirmed histologically and the features include normal pituitary with lymphocytic infiltration, plasma cells, histiocytes and fibrosis. Treatment includes replacement of hormone deficiency (including $\mathrm{ADH})$ and decision making regarding conservative, 


\section{Management algorithm for the patient with hypophysitis}



Figure 1

Early assessment for treatment response with pituitary MRI. Follow with serial imaging until clear stability, maintain clinical suspicion for recurrence. Consider escalating to immunosuppression or radiotherapy if persistent symptoms or continuing mass effect despite corticosteroids \pm surgery.

medical and surgical therapies. High-dose suppressive glucocorticoid remains the cornerstone of medical therapy but a variety of immunosuppressive treatments have been used. Surgery is indicated for non-responders, mass effect, headache, visual failure or when a tissue diagnosis is considered important. Radiotherapy may be useful when there is relapse of disease and some patients require multi-modal treatment. There have been comprehensive reviews of LH and we have purposefully limited the discussion $(1,3,4,5)$ in this review.

\section{Granulomatous hypophysitis}

4. Granulomatous hypophysitis is the second commonest type of primary hypophysitis (10). Granulomatous disease can be seen as a primary entity (known as idiopathic primary granulomatous hypophysitis) or secondary to a systemic pathology such as sarcoidosis, tuberculosis or granulomatosis with polyangitis (previously known as Wegener's granulomatosis). In less than a hundred reported cases of the primary condition, five have been associated with the postpartum state (39). The histology is characterised by the presence of multinucleated giant cells, histiocytes, lymphocyte infiltration along with plasma cells (40). It is still unclear if granulomatous changes form a continuum of the lymphocytic inflammatory processes (33). There has been reported female predominance in a systematic review of idiopathic cases (40). The clinical presentation tends to be more severe with higher incidence of visual symptoms compared to LH $(10,40)$. In a review of 31 patients, Gutenberg et al. identified that gonadotrophin deficiency was present in $100 \%$ cases with granulomatous disease (33). Systemic symptoms such as a fever, nausea and vomiting were reported to correlate with earlier presentation (40). The radiological appearance does not help differentiate between different types. The presence of immunological markers of systemic conditions can help identify the secondary granulomatous disease (Table 3). Glucocorticoid therapy appears to be less effective compared with LH (33) while surgical resection leads to better symptom resolution (40).

5. Xanthomatous hypophysitis

6. Xanthomatous hypophysitis $(\mathrm{XH})$ is considered to be the rarest of the histological types. Only 18 cases 
have been reported since the first published in 1998 $(41,42)$. It is unclear if $\mathrm{XH}$ constitutes a distinct entity or is a possible extension of the autoimmune or lymphocytic spectrum. As seen with xanthomatous lesions elsewhere in the body, it is postulated that xanthomatous infiltration results from macrophage activation secondary to chronic inflammation (42). It has been more commonly reported in females (43). The clinical presentation is thought to be similar to $\mathrm{LH}$, but visual symptoms are considered to be rare (33, 43). The clinical symptoms appear to be milder and present for a longer duration in the patients compared to other types of hypophysitis (33). Similarly, DI is rarely reported with xanthomatous presentation (33).

7. Xanthomatous lesions present radiologically as cystic sellar masses on MRI and enhance on the post-gadolinium contrast images. The gross lesion appears as a cyst filled with thick orange coloured fluid with floating crystals $(42,43)$. The diagnosis is only confirmed on tissue sections demonstrating xanthoma cells or lipid-laden macrophages in the pituitary tissue. Immunostaining highlights CD68 glycoprotein and can be utilised as tool to mark macrophage-related pathology $(42,43)$. It has been suggested that $\mathrm{XH}$ may be less responsive to steroid therapy, as compared to LH but as clinical experience is extremely limited this is yet to be established. Given the reported lack of effectiveness of medical management, most lesions are treated with surgery, if not already operated on for diagnostic purposes (42). The response to treatment varies from complete, partial or no recovery from mass effect of symptoms, but endocrine deficiencies seldom recover $(44,45)$.

8. IgG4-related disease

9. IgG4-related hypophysitis was first reported in 2004 (46). It is believed to be rare but a recent retrospective histological review of cases, previously thought to demonstrate LH showed that $41 \%(12 / 29)$ were reclassified as IgG4 hypophysitis (47). The previous lack of recognition of this aetiology indicates that cases previously classified as 'hypophysitis' or 'lymphocytic hypophysitis' may in fact reflect IgG4-RD. It is likely that further retro- and prospective studies will help us understand whether IgG4-RD represents a substantial cohort within the hypophysitis spectrum of diseases. While the exact aetiology still remains unclear, an association with autoimmune and atopic conditions has been frequently reported $(48,49)$. In a recent paper, Della Torre et al. debated against the role of atopy in
IgG4 disease, which remains to be confirmed (49, 50). The exact role of IgG4 in pathogenesis remains elusive, and it may well be considered a 'bystander' in the inflammatory phenomenon (51).

10. The condition commonly presents as pseudo-tumour lesions with IgG4-dominant plasmacytic infiltration of multiple organs $(52,53,54)$. IgG4-related disease has been more commonly reported in middle-aged and elderly populations, with male predominance $(48,54,55)$, except for a recent study where authors suggested a distinct subset of IgG4 disease with female predominance (47). The commonest co-existent IgG4related pathology associated with pituitary disease is retroperitoneal fibrosis (56).

11. A consensus statement described histological findings of IgG4-related disease and a prerequisite criteria with two out of the three features namely, dense lymphoplasmacytic infiltrate, storiform fibrosis and obliterative phlebitis. There have been other diseasespecific guidelines, which report exceptions to these guidelines $(47,57)$. Leporati et al. suggested a pituitary disease-specific diagnostic criteria for confirmation of the disease (52). In a retrospective review of primary hypophysitis, Bernreuther et al. suggested that presence of lymphoplasmacytic infiltrate should be used as a prerequisite to test for IgG4 staining. The presence of more than ten IgG4-positive cells per high power field and a ratio of IgG4/IgG-positive cells of more than $40 \%$ was noted in all patients with confirmed IgG4 hypophysitis (47). These findings have been debated by others (58).

12. Serum levels of IgG4 are not sensitive or specific for IgG4-RD and elevated levels tend to normalise with steroid therapy making them less useful as diagnostic tool $(56,58)$. It is recommended that laboratories reporting IgG4 should confirm freedom from prozoning (hook) effect (59). Wallace et al. suggested that those with elevated serum IgG4 could represent a subset of patients with multi-organ involvement (60). In a recent report, Landek-Salgado et al. demonstrated autoantigens against growth hormone and POMC in a biopsy proven IgG4-hypophysitis patient (61). The significance of the finding or its applicability to other types of hypophysitis is uncertain. The radiologic features are not distinct from other types of hypophysitis. There is an evolving role of the use of FDG PET in IgG4-related disease to characterise systemic involvement of tissues. Steroids form the mainstay of treatment with a beneficial early response, but recovery of endocrine function is thought to be 
uncommon (56). There is a potential role for the use of B-cell-depleting therapies $(62,63)$.

\section{Langerhans cell histiocytosis}

14. LCH is a rare inflammatory disease, with an incidence of $1-2$ cases per million in adults $(64,65)$, though it is more commonly reported in the paediatric population. The exact pathogenesis of the condition is still debated. It has a variable unpredictable course, often ranging from a self-limiting course to a rapidly progressive form (66). Often diabetes insipidus is one of the earliest manifestations, denoting the predilection for involvement of the hypothalamic-pituitary axis (65). Anterior pituitary deficiencies are less common, but nonetheless have been reported in approximately $20 \%$ of patients (66). Growth hormone deficiency is most common, followed by gonadotrophin deficiency, as reported in paediatric studies $(67,68)$. Prolactin elevation is considered as a possible result of stalk involvement (69), with disinhibition. Patients with multisystem involvement are more likely to have DI associated with multiple endocrine insufficiencies.

15. Diagnosis is suspected when there are other multisystem features or the presence of diabetes insipidus. While confirmation of the diagnosis is based on histological and immunological criteria (Table 3), a skeletal survey and chest X-ray could be the first-line imaging investigations (66). MRI findings are not specific to $\mathrm{LCH}$, and different patterns of pituitary involvement have been reported. While absence of posterior pituitary bright spot is most common, other features such as stalk thickening, pituitary enlargement, empty sella and hypothalamic involvement have all been described (65). PET imaging may be used to guide response to therapy or identification of active disease (66). It also has a role in allowing clarification of the diagnosis by identifying sites of disease more amenable to biopsy than the pituitary gland. Treatment commonly involves an immune-suppressive regimen, chemotherapy or radiotherapy and unlike in children, it has not yet been standardised for adult patients (66). Hormone replacement therapies should be initiated as soon as the diagnosis is established. Vinblastine and steroidbased therapy are suggested as the first-line options by the Histiocyte Society Guidance (70). An initial 6-week induction regimen is followed by 12 months of maintenance therapy to reduce the risk of reactivation (70). Radiotherapy (lower doses than for pituitary adenoma) results in partial or transient resolution of radiological abnormalities (65). While the radiological lesion seems to regress with treatment, recovery of endocrine deficiencies is rare (71). New-onset DI, in a patient previously considered to be in remission, might be a sign of reactivation of the disease (65).

\section{Immune checkpoint therapy-related} hypophysitis

17. With the introduction of novel immune targeted therapy for a variety of cancers, there has been a rise of immune-mediated systemic adverse events. Ipilimumab (CTLA4 antibody) was the first immune checkpoint inhibitor licensed for the use in malignant melanoma (72). More recently nivolumab (PD1 antibody), pembrolizumab (PD1 antibody) and combination therapies are being used for a number of metastatic malignancies. Hypophysitis is a recognised side effect of these agents (73). Pituitary inflammation with immune checkpoint inhibitor-related therapies appears to have a higher incidence in males and the elderly, unlike LH (74). The incidence is commonly noted prior to the third cycle of treatment and ranges from 5 to 36 weeks from the onset of the oncological therapy, with a mean duration of 9 weeks (75). The clinical presentation is similar to other forms of hypophysitis, in relation to the symptoms and requires a high index of suspicion. Headache has been reported in several studies. All patients receiving immune checkpoint therapy with new onset headache or suspected cortisol deficiency should be evaluated for the likelihood of hypophysitis (76). Caturegli et al. have recently summarised the differences between immune checkpoint therapy (CTLA-4)-induced hypophysitis and primary (lymphocytic) hypophysitis (76). The incidence of visual disturbances and diabetes insipidus is extremely rare $(73,76)$. Endocrine deficiencies are noted in more than $70 \%$ patients and include high rates of thyrotrophin, gonadotrophin as well as corticotroph insufficiency (77). Little is known about GH status. While the trend to recovery is very variable in most primary hypophysitis, recovery of ACTH insufficiency is very rare in CTLA-4-induced hypophysitis $(76,77)$.

18. There are no obvious radiological patterns, which differentiate primary and drug-induced hypophysitis and as has been reported, the radiological findings can precede clinical diagnosis by several weeks (74). The use of FDG PET in these oncology patients has a potential to identify radiological evidence of additional sites of immune-mediated adverse effects. Numerous case reports highlighted the incidental detection of hypophysitis, pancreatitis, adrenalitis 
and thyroiditis, when PET was used for surveillance purposes $(78,79,80,81)$.

19. Caterugli et al. have described the biopsy findings of CTLA-4 related hypophysitis (76). They have demonstrated pathological findings of complement fixation, macrophage infiltration and lymphocyte activation confirming that the mechanism of CTLA4-related hypophysitis is largely a result of type II and type IV hypersensitivity reaction. Iwama et al. were the first to report to the presence of CTLA-4 Ag in pituitary tissue and suggest antibody-dependent complement activation (ADCC) as the underlying model of immune activation (82). Nivolumab and pembrolizumab are IgG4-based PD1 antibodies and less likely to be able to mount a similar ADCC-mediated response (83). PD1 expression on pituitary cells has not been investigated. Further details of the mechanism are beyond the scope of this review and increased understanding of the precise pathophysiological mechanism(s) responsible for immune therapy-related hypophysitis is required.

20. The management of immune checkpoint therapyrelated hypophysitis depends on the severity of the clinical presentations graded by the CTCAE grading system in oncology trials (73). For milder dysfunction, the treatment involves replacing the hormone deficiency as standard (73). But in severe or life-threatening cases, the role of high-dose steroids and discontinuation of the oncology therapy needs consideration $(73,84)$. Many centres are developing local guidelines to help clinicians identify iRAEs and manage acute and chronic complications of immune checkpoint therapies.

\section{Recent advances in the understanding of hypophysitis: imaging modalities and immunomarkers}

In recent years, a novel entity called 'Anti-Pit 1 antibody syndrome' has been recognised (85). This presents as an acquired deficiency of growth hormone, TSH and prolactin with detectable anti-Pit 1 antibody (26). It is considered to be a cytotoxic $\mathrm{T}$ cell-mediated autoimmune process, but further studies are needed to establish the exact pathogenesis (86). Similarly antibody to pituitary tissue has been identified as a possible antigenic target in $\mathrm{LH}$, even in patients not presenting with ACTH deficiency (87). Heaney et al. have suggested that use of HLA markers for DQ8 and DR53 could be used to identify patients suspected to have LH. There is a 23.1-fold increase in the levels of DQ8 in the patients with LH as compared to those with other pituitary lesions (88).

The use of nuclear medicine in the diagnosis of inflammatory conditions has been evolving. Recently Lee et al. used FDG PET in IgG4-related diseases. They reported that pattern of uptake and multi-organ involvement were significant predictors of IgG4-related disease (89). The use of software-based image processing technology called textural analysis has been suggested to differentiate neoplastic and non-neoplastic PS lesions with more certainty. The distribution of the grey levels in the given region of interest could be used as a guiding tool to determine, which lesions are less likely to be inflammatory and facilitate decision making (90). In clinical practice, FDG PET has become an increasingly used tool in the assessment of the patient with inflammatory pituitary conditions, often allowing diagnosis to be made by facilitating less invasive tissue biopsy in multisite disease.

\section{Anticipated future developments}

Interest in inflammatory disorders affecting the pituitary gland has increased in recent years. Recognition of IgG4-RD has prompted reconsideration of the classification of hypophysitis and clinicians are considering this diagnosis both in new prospective cases and in historic ones labelled as LH (often without biopsy). The advent of immune checkpoint inhibition has meant an increase in clinical experience with hypophysitis for endocrine physicians and provides insight into the pathophysiological mechanisms of disease. These increases in understanding will likely result in new diagnostic algorithms and more accurate classification of disease. New serological markers are likely to emerge and non-invasive diagnostics will improve. The near future will likely see more accurate diagnosis of primary and secondary hypophysitis and lead to more consistent and specific treatments for this rare group of disorders. Collaborative multi-centre prospective studies are required to define the optimal treatment approaches for the patient with hypophysitis.

Supplementary data

This is linked to the online version of the paper at https://doi.org/10.1530/ EJE-17-0009.

Declaration of interest

The authors declare that there is no conflict of interest that could be perceived as prejudicing the impartiality of this review. 
Funding

This research did not receive any specific grant from any funding agency in the public, commercial or not-for-profit sector.

\section{References}

1 Kirshbaum JD \& Levy HA. Tuberculoma of hypophysis with insufficiency of anterior lobe: a clinical and pathologic study of two cases. Archives of Internal Medicine 194168 1095-1104. (https://doi. org/10.1001/archinte.1941.00200120054004)

2 De Giorgi L. Interstitial lymphocytic hypophysitis in premature separation of normally inserted placenta. Archivio di Ostetricia e Ginecologia 195055 311-328.

3 Goudie RB \& Pinkerton PH. Anterior hypophysitis and Hashimoto's disease in a young woman. Journal of Pathology and Bacteriology 1962 83 584-585. (https://doi.org/10.1002/path.1700830241)

4 Caturegli P, Newschaffer C, Olivi A, Pomper MG, Burger PC \& Rose NR. Autoimmune hypophysitis. Endocrine Reviews 200526 599-614. (https://doi.org/10.1210/er.2004-0011)

5 Bellastella G, Maiorino MI, Bizzarro A, Giugliano D, Esposito K, Bellastella A \& De Bellis A. Revisitation of autoimmune hypophysitis: knowledge and uncertainties on pathophysiological and clinical aspects. Pituitary 201619 625-642. (https://doi.org/10.1007/s11102016-0736-z)

6 Caturegli P, Lupi I, Landek-Salgado M, Kimura H \& Rose NR. Pituitary autoimmunity: 30 years later. Autoimmunity Reviews 20087 631-637. (https://doi.org/10.1016/j.autrev.2008.04.016)

7 Sautner D, Saeger W, Lüdecke DK, Jansen V \& Puchner MJ. Hypophysitis in surgical and autoptical specimens. Acta Neuropathologica 199590 637-644. (https://doi.org/10.1007/BF00318578)

8 Kartal I, Yarman S, Tanakol R \& Bilgic B. Lymphocytic panhypophysitis in a young man with involvement of the cavernous sinus and clivus. Pituitary 200710 75-80. (https://doi.org/10.1007/ s11102-007-0003-4)

9 Falorni A, Minarelli V, Bartoloni E, Alunno A \& Gerli R. Diagnosis and classification of autoimmune hypophysitis. Autoimmunity Reviews 201413 412-416. (https://doi.org/10.1016/j. autrev.2014.01.021)

10 Honegger J, Schlaffer S, Menzel C, Droste M, Werner S, Elbelt U, Strasburger C, Störmann S, Küppers A, Streetz-van der Werf C et al. Diagnosis of primary hypophysitis in Germany. Journal of Clinical Endocrinology and Metabolism 2015100 3841-3849. (https://doi. org/10.1210/jc.2015-2152)

11 Fujiwara T, Ota K, Kakudo N, Rikimaru S, Sugawara T, Yamada K, Satoh T, Yano M, Tamate E, Miura M et al. Idiopathic giant cell granulomatous hypophysitis with hypopituitarism, right abducens nerve paresis and masked diabetes insipidus. Internal Medicine 2001 40 915-919. (https://doi.org/10.2169/internalmedicine.40.915)

12 Ikeda J, Kuratsu J, Miura M, Kai Y \& Ushio Y. Lymphocytic adenohypophysitis accompanying occlusion of bilateral internal carotid arteries - case report. Neurologia Medico-Chirurgica 199030 346-349. (https://doi.org/10.2176/nmc.30.346)

13 Katoh N, Machida K, Satoh S, Yahikozawa H \& Ikeda S. A clinically diagnosed lymphocytic hypophysitis presenting as recurrent meningitis. Rinsho Shinkeigaku 200747 419-422.

14 Husain Q, Zouzias A, Kanumuri VV, Eloy JA \& Liu JK. Idiopathic granulomatous hypophysitis presenting as pituitary apoplexy. Journal of Clinical Neuroscience 201421 510-512. (https://doi.org/10.1016/j. jocn.2013.05.002)

15 Turcu AF, Erickson BJ, Lin E, Guadalix S, Schwartz K, Scheithauer BW, Atkinson JL \& Young WF Jr. Pituitary stalk lesions: the Mayo Clinic experience. Journal of Clinical Endocrinology and Metabolism 201398 1812-1818. (https://doi.org/10.1210/jc.2012-4171)

16 Saiwai S, Inoue Y, Ishihara T, Matsumoto S, Nemoto Y, Tashiro T, Hakuba A \& Miyamoto T. Lymphocytic adenohypophysitis: skull radiographs and MRI. Neuroradiology 199840 114-120. (https://doi. org/10.1007/s002340050550)

17 Gao H, Gu YY \& Qiu MC. Autoimmune hypophysitis may eventually become empty sella. Neuro Endocrinology Letters 201334 102-106.

18 Gutenberg A, Larsen J, Lupi I, Rohde V \& Caturegli P. A radiologic score to distinguish autoimmune hypophysitis from nonsecreting pituitary adenoma preoperatively. American Journal of Neuroradiology 200930 1766-1772. (https://doi.org/10.3174/ajnr.A1714)

19 Jian F, Bian L, Sun S, Yang J, Chen X, Chen Y, Ma Q, Miao F, Wang W, Ning $\mathrm{G}$ et al. Surgical biopsies in patients with central diabetes insipidus and thickened pituitary stalks. Endocrine 201447 325-335. (https://doi.org/10.1007/s12020-014-0184-3)

20 Tokue A, Higuchi T, Arisaka Y, Nakajima T, Tokue H \& Tsushima Y. Role of F-18 FDG PET/CT in assessing IgG4-related disease with inflammation of head and neck glands. Annals of Nuclear Medicine 201529 499-505. (https://doi.org/10.1007/s12149-015-0969-3)

21 Lee HJ, Ahn BC, Lee SW \& Lee J. The usefulness of F-18 fluorodeoxyglucose positron emission tomography/computed tomography in patients with Langerhans cell histiocytosis. Annals of Nuclear Medicine 201226 730-737. (https://doi.org/10.1007/s12149012-0635-y)

22 Crock PA. Cytosolic autoantigens in lymphocytic hypophysitis. Journal of Clinical Endocrinology and Metabolism 199883 609-618. (https://doi.org/10.1210/jcem.83.2.4563)

23 Bensing S, Hulting AL, Höög A, Ericson K \& Kämpe O. Lymphocytic hypophysitis: report of two biopsy-proven cases and one suspected case with pituitary autoantibodies. Journal of Endocrinological Investigation 200730 153-162. (https://doi.org/10.1007/BF03347415)

24 Lupi I, Broman KW, Tzou SC, Gutenberg A, Martino E \& Caturegli P. Novel autoantigens in autoimmune hypophysitis. Clinical Endocrinology 200869 269-278. (https://doi.org/10.1111/j.13652265.2008.03180.x)

25 Tanaka S, Tatsumi KI, Kimura M, Takano T, Murakami Y, Takao T, Hashimoto K, Kato Y \& Amino N. Detection of autoantibodies against the pituitary-specific proteins in patients with lymphocytic hypophysitis. European Journal of Endocrinology 2002147 767-775. (https://doi.org/10.1530/eje.0.1470767)

26 Yamamoto M, Iguchi G, Takeno R, Okimura Y, Sano T, Takahashi M, Nishizawa $\mathrm{H}$, Handayaningshi AE, Fukuoka $\mathrm{H}$, Tobita $\mathrm{M}$ et al. Adult combined GH, prolactin, and TSH deficiency associated with circulating PIT-1 antibody in humans. Journal of Clinical Investigation 2011121 113-119. (https://doi.org/10.1172/JCI44073)

27 Iwama S, Sugimura Y, Kiyota A, Kato T, Enomoto A, Suzuki H, Iwata N, Takeuchi S, Nakashima K, Takagi H et al. Rabphilin-3A as a targeted autoantigen in lymphocytic infundibulo-neurohypophysitis. Journal of Clinical Endocrinology and Metabolism 2015100 E946-E954. (https://doi.org/10.1210/jc.2014-4209)

28 Ricciuti A, Remigis A, Landek-Salgado MA, Vincentiis L, Guaraldi F, Lupi I, Iwama S, Wand GS, Salvatori R \& Caturegli P. Detection of pituitary antibodies by immunofluorescence: approach and results in patients with pituitary diseases. Journal of Clinical Endocrinology and Metabolism 201499 1758-1766. (https://doi.org/10.1210/jc.2014-1049)

29 Kleinschmidt-DeMasters BK \& Lopes MB. Update on hypophysitis and TTF-1 expressing sellar region masses. Brain Pathology 201323 495-514. (https://doi.org/10.1111/bpa.12068)

30 Fleseriu M, Hashim IA, Karavitaki N, Melmed S, Murad MH, Salvatori R \& Samuels MH. Hormonal replacement in hypopituitarism in adults: an Endocrine Society Clinical Practice Guideline. Journal of Clinical Endocrinology and Metabolism 2016101 3888-3921. (https://doi.org/10.1210/jc.2016-2118)

31 Honegger J, Buchfelder M, Schlaffer S, Droste M, Werner S, Strasburger C, Störmann S, Schopohl J, Kacheva S, Deutschbein T et al. Treatment of primary hypophysitis in Germany. Journal of Clinical Endocrinology and Metabolism 2015100 3460-3469. (https:// doi.org/10.1210/jc.2015-2146)

32 Leung GK, Lopes MB, Thorner MO, Vance ML \& Laws ER. Primary hypophysitis: a single-center experience in 16 cases. Journal 
of Neurosurgery 2004101 262-271. (https://doi.org/10.3171/ jns.2004.101.2.0262)

33 Gutenberg A, Hans V, Puchner MJ, Kreutzer J, Brück W, Caturegli P \& Buchfelder M. Primary hypophysitis: clinical-pathological correlations. European Journal of Endocrinology 2006155 101-107. (https://doi.org/10.1530/eje.1.02183)

34 Khare S, Jagtap VS, Budyal SR, Kasaliwal R, Kakade HR, Bukan A, Sankhe S, Lila AR, Bandgar T, Menon PS et al. Primary (autoimmune) hypophysitis: a single centre experience. Pituitary 201518 16-22. (https://doi.org/10.1007/s11102-013-0550-9)

35 Beressi N, Beressi JP, Cohen R \& Modigliani E. Lymphocytic hypophysitis. A review of 145 cases. Annales de Médecine Interne 1999 $150327-341$

36 Eli IM, Raheja A, Corn HJ, Simmons DL, Palmer CA \& Couldwell WT. Sellar wegener granulomatosis masquerading as cabergoline-resistant prolactinoma. World Neurosurgery 201695 622.e1-622.e5. (https:// doi.org/10.1016/j.wneu.2016.07.108)

37 Krysiak R, Samborek M \& Stojko R. Anti-inflammatory effects of bromocriptine in a patient with autoimmune polyglandular syndrome type 2. Neuro Endocrinology Letters 201435 179-182.

38 Shelly S, Boaz M \& Orbach H. Prolactin and autoimmunity. Autoimmunity Reviews 201211 A465-A470. (https://doi. org/10.1016/j.autrev.2011.11.009)

39 Joneja U, Hooper DC, Evans JJ \& Curtis MT. Postpartum granulomatous hypophysitis: a case study, review of the literature, and discussion of pathogenesis. Case Reports in Pathology 20162016 7510323. (https://doi.org/10.1155/2016/7510323)

40 Hunn BH, Martin WG, Simpson S Jr \& McLean CA. Idiopathic granulomatous hypophysitis: a systematic review of 82 cases in the literature. Pituitary 201417 357-365. (https://doi.org/10.1007/ s11102-013-0510-4)

41 Folkerth RD, Price DL Jr, Schwartz M, Black PM \& De Girolami U. Xanthomatous hypophysitis. American Journal of Surgical Pathology 199822 736-741. (https://doi.org/10.1097/00000478-19980600000011)

42 Hanna B, Li YM, Beutler T, Goyal P \& Hall WA. Xanthomatous hypophysitis. Journal of Clinical Neuroscience 201522 1091-1097. (https://doi.org/10.1016/j.jocn.2015.01.019)

43 Aste L, Bellinzona M, Meleddu V, Farci G, Manieli C \& Godano U. Xanthomatous hypophysitis mimicking a pituitary adenoma: case report and review of the literature. Journal of Oncology 20102010 195323. (https://doi.org/10.1155/2010/195323)

44 Gutenberg A, Buslei R, Fahlbusch R, Buchfelder M \& Brück W. Immunopathology of primary hypophysitis: implications for pathogenesis. American Journal of Surgical Pathology 200529 329-338. (https://doi.org/10.1097/01.pas.0000149707.12335.8e)

45 Burt MG, Morey AL, Turner JJ, Pell M, Sheehy JP \& Ho KK. Xanthomatous pituitary lesions: a report of two cases and review of the literature. Pituitary 20036 161-168. (https://doi.org/10.1023/ B:PITU.0000011177.43408.56)

46 Vliet HJ \& Perenboom RM. Multiple pseudotumors in IgG4associated multifocal systemic fibrosis. Annals of Internal Medicine 2004141 896-897. (https://doi.org/10.7326/0003-4819-141-11200412070-00033)

47 Bernreuther C, Illies C, Flitsch J, Buchfelder M, Buslei R, Glatzel M \& Saeger W. IgG4-related hypophysitis is highly prevalent among cases of histologically confirmed hypophysitis. Brain Pathology 201627 839-845. (https://doi.org/10.1111/bpa.12459)

48 Wallace ZS \& Stone JH. An update on IgG4-related disease. Current Opinion in Rheumatology 201527 83-90. (https://doi.org/10.1097/ BOR.0000000000000133)

49 Stone JH, Chan JK, Deshpande V, Okazaki K, Umehara H \& Zen Y. IgG4-related disease. International Journal of Rheumatology 20132013 532612 .

50 Della Torre E, Mattoo H, Mahajan VS, Carruthers M, Pillai S \& Stone JH. Prevalence of atopy, eosinophilia, and IgE elevation in IgG4-related disease. Allergy 201469 269-272. (https://doi. org/10.1111/all.12320)

51 Iwata N, Iwama S, Sugimura Y, Yasuda Y, Nakashima K, Takeuchi S, Hagiwara D, Ito Y, Suga H, Goto M et al. Anti-pituitary antibodies against corticotrophs in IgG4-related hypophysitis. Pituitary 201620 301-310. (https://doi.org/10.1007/s11102-016-0780-8)

52 Leporati P, Landek-Salgado MA, Lupi I, Chiovato L \& Caturegli P. IgG4-related hypophysitis: a new addition to the hypophysitis spectrum. Journal of Clinical Endocrinology and Metabolism 201196 1971-1980. (https://doi.org/10.1210/jc.2010-2970)

53 Hori M, Makita N, Andoh T, Takiyama H, Yajima Y, Sakatani T, Fukumoto S, Iiri T \& Fujita T. Long-term clinical course of IgG4related systemic disease accompanied by hypophysitis. Endocrine Journal 201057 485-492. (https://doi.org/10.1507/endocrj.K09E-356)

54 Stone JH, Zen Y \& Deshpande V. IgG4-related disease. New England Journal of Medicine 2012366 539-551. (https://doi.org/10.1056/ NEJMra1104650)

55 Shimatsu A, Oki Y, Fujisawa I \& Sano T. Pituitary and stalk lesions (infundibulo-hypophysitis) associated with immunoglobulin G4-related systemic disease: an emerging clinical entity. Endocrine Journal 200956 1033-1041. (https://doi.org/10.1507/endocrj.K09E277)

56 Bando H, Iguchi G, Fukuoka H, Taniguchi M, Yamamoto M, Matsumoto R, Suda K, Nishizawa H, Takahashi M, Kohmura E et al. The prevalence of IgG4-related hypophysitis in 170 consecutive patients with hypopituitarism and/or central diabetes insipidus and review of the literature. European Journal of Endocrinology 2014170 161-172. (https://doi.org/10.1530/EJE-13-0642)

57 Deshpande V, Zen Y, Chan JK, Yi EE, Sato Y, Yoshino T, Klöppel G, Heathcote JG, Khosroshahi A, Ferry JA et al. Consensus statement on the pathology of IgG4-related disease. Modern Pathology 201225 1181-1192. (https://doi.org/10.1038/modpathol.2012.72)

58 Carruthers MN, Khosroshahi A, Augustin T, Deshpande V \& Stone JH. The diagnostic utility of serum IgG4 concentrations in IgG4-related disease. Annals of the Rheumatic Diseases 2015 74 14-18. (https://doi.org/10.1136/annrheumdis-2013-204907)

59 Egner W, Swallow K, Lock RJ \& Patel D. Falsely low immunoglobulin (Ig)G4 in routine analysis: how not to miss IgG4 disease. Clinical and Experimental Immunology 2016186 57-63. (https://doi.org/10.1111/ cei.12805)

60 Wallace ZS, Deshpande V, Mattoo H, Mahajan VS, Kulikova M, Pillai S \& Stone JH. IgG4-related disease: clinical and laboratory features in one hundred twenty-five patients. Arthritis and Rheumatology 201567 2466-2475. (https://doi.org/10.1002/ art.39205)

61 Landek-Salgado MA, Leporati P, Lupi I, Geis A \& Caturegli P. Growth hormone and proopiomelanocortin are targeted by autoantibodies in a patient with biopsy-proven IgG4-related hypophysitis. Pituitary 201215 412-419. (https://doi.org/10.1007/s11102-011-0338-8)

62 Carruthers MN, Topazian MD, Khosroshahi A, Witzig TE, Wallace ZS, Hart PA, Deshpande V, Smyrk TC, Chari S \& Stone JH. Rituximab for IgG4-related disease: a prospective, open-label trial. Annals of the Rheumatic Diseases 201574 1171-1177. (https://doi.org/10.1136/ annrheumdis-2014-206605)

63 Wallace ZS, Mattoo H, Mahajan VS, Kulikova M, Lu L, Deshpande V, Choi HK, Pillai S \& Stone JH. Predictors of disease relapse in IgG4related disease following rituximab. Rheumatology $2016 \mathbf{5 5}$ 1000-1008. (https://doi.org/10.1093/rheumatology/kev438)

64 Baumgartner I, von Hochstetter A, Baumert B, Luetolf U \& Follath F. Langerhans'-cell histiocytosis in adults. Medical and Pediatric Oncology 199728 9-14. (https://doi.org/10.1002/(SICI)1096911X(199701)28:1<9::AID-MPO3>3.0.CO;2-P)

65 Makras P, Alexandraki KI, Chrousos GP, Grossman AB \& Kaltsas GA. Endocrine manifestations in Langerhans cell histiocytosis. Trends in Endocrinology and Metabolism 200718 252-257. (https://doi. org/10.1016/j.tem.2007.06.003) 
66 Girschikofsky M, Arico M, Castillo D, Chu A, Doberauer C, Fichter J, Haroche J, Kaltsas GA, Makras P, Marzano AV et al. Management of adult patients with Langerhans cell histiocytosis: recommendations from an expert panel on behalf of Euro-Histio-Net. Orphanet Journal of Rare Diseases 20138 72. (https://doi.org/10.1186/1750-1172-8-72)

67 Nanduri VR, Bareille P, Pritchard J \& Stanhope R. Growth and endocrine disorders in multisystem Langerhans' cell histiocytosis. Clinical Endocrinology 200053 509-515. (https://doi.org/10.1046/ j.1365-2265.2000.01125.x)

68 Donadieu J, Rolon MA, Thomas C, Brugieres L, Plantaz D, Emile JF, Frappaz D, David M, Brauner R, Genereau T et al. Endocrine involvement in pediatric-onset Langerhans' cell histiocytosis: a population-based study. Journal of Pediatrics 2004144 344-350. (https://doi.org/10.1016/j.jpeds.2003.12.030)

$69 \mathrm{Su}$ C. Hypophysitis mimicking a pituitary adenoma (report of 3 cases). Zhongguo Yi Xue Ke Xue Yuan Xuе Bao 199113 376-379.

70 Minkov M, Grois N, McClain K, Nanduri V, Rodriguez-Galindo C, Simonitsch-Klupp I, Visser J, Weitzmann S, Whitlock J \& Windebank K. Langerhans cell histiocytosis - histiocyte society evaluation and treatment guidelines. (available from: http://www. histiocytesociety.org/document.doc?id=2902009)

71 Makras P, Samara C, Antoniou M, Zetos A, Papadogias D, Nikolakopoulou Z, Andreakos E, Toloumis G, Kontogeorgos G, Piaditis $\mathrm{G}$ et al. Evolving radiological features of hypothalamopituitary lesions in adult patients with Langerhans cell histiocytosis (LCH). Neuroradiology 200648 37-44. (https://doi.org/10.1007/ s00234-005-0011-x)

72 Hanaizi Z, van Zwieten-Boot B, Calvo G, Lopez AS, van Dartel M, Camarero J, Abadie E \& Pignatti F. The European Medicines Agency review of ipilimumab (Yervoy) for the treatment of advanced (unresectable or metastatic) melanoma in adults who have received prior therapy: summary of the scientific assessment of the Committee for Medicinal Products for Human Use. European Journal of Cancer 201248 237-242. (https://doi.org/10.1016/j. ejca.2011.09.018)

73 Joshi MN, Whitelaw BC, Palomar MT, Wu Y \& Carroll PV. Immune checkpoint inhibitor-related hypophysitis and endocrine dysfunction: clinical review. Clinical Endocrinology 201685 331-339. (https://doi.org/10.1111/cen.13063)

74 Faje AT, Sullivan R, Lawrence D, Tritos NA, Fadden R, Klibanski A \& Nachtigall L. Ipilimumab-induced hypophysitis: a detailed longitudinal analysis in a large cohort of patients with metastatic melanoma. Journal of Clinical Endocrinology and Metabolism 201499 4078-4085. (https://doi.org/10.1210/jc.2014-2306)

75 Min L, Hodi FS, Giobbie-Hurder A, Ott PA, Luke JJ, Donahue H, Davis M, Carroll RS \& Kaiser UB. Systemic high-dose corticosteroid treatment does not improve the outcome of ipilimumab-related hypophysitis: a retrospective cohort study. Clinical Cancer Research 201521 749-755. (https://doi.org/10.1158/1078-0432.CCR-14-2353)

76 Caturegli P, Di Dalmazi G, Lombardi M, Grosso F, Larman HB, Larman T, Taverna G, Cosottini M \& Lupi I. Hypophysitis secondary to cytotoxic T-lymphocyte-associated protein 4 blockade: insights into pathogenesis from an autopsy series. American Journal of Pathology 2016186 3225-3235. (https://doi.org/10.1016/j. ajpath.2016.08.020)

77 Albarel F, Gaudy C, Castinetti F, Carré T, Morange I, Conte-Devolx B, Grob JJ \& Brue T. Long-term follow-up of ipilimumab-induced hypophysitis, a common adverse event of the anti-CTLA- 4 antibody in melanoma. European Journal of Endocrinology 2015172 195-204. (https://doi.org/10.1530/EJE-14-0845)
78 Wachsmann JW, Ganti R \& Peng F. Immune-mediated disease in ipilimumab immunotherapy of melanoma with FDG PET-CT. Academic Radiology 201724 111-115. (https://doi.org/10.1016/j. acra.2016.08.005)

79 Alabed YZ, Aghayev A, Sakellis C \& Van den Abbeele AD. Pancreatitis secondary to anti-programmed death receptor 1 immunotherapy diagnosed by FDG PET/CT. Clinical Nuclear Medicine $2015 \mathbf{4 0}$ e528-e529. (https://doi.org/10.1097/RLU.0000000000000940)

80 Bacanovic S, Burger IA, Stolzmann P, Hafner J \& Huellner MW. Ipilimumab-induced adrenalitis: a possible pitfall in 18F-FDG-PET/ CT. Clinical Nuclear Medicine 201540 e518-e519. (https://doi. org/10.1097/RLU.0000000000000887)

81 van der Hiel B, Blank CU, Haanen JB \& Stokkel MP. Detection of early onset of hypophysitis by (18)F-FDG PET-CT in a patient with advanced stage melanoma treated with ipilimumab. Clinical Nuclear Medicine 201338 e182-e184. (https://doi.org/10.1097/ RLU.0b013e3182639765)

82 Iwama S, De Remigis A, Callahan MK, Slovin SF, Wolchok JD \& Caturegli P. Pituitary expression of CTLA-4 mediates hypophysitis secondary to administration of CTLA-4 blocking antibody. Science Translational Medicine 20146 230ra45. (https://doi.org/10.1126/ scitranslmed.3008002)

83 Vidarsson G, Dekkers G \& Rispens T. IgG subclasses and allotypes: from structure to effector functions. Frontiers in Immunology 20145 520. (https://doi.org/10.3389/fimmu.2014.00520)

84 Faje A. Immunotherapy and hypophysitis: clinical presentation, treatment, and biologic insights. Pituitary 201619 82-92. (https:// doi.org/10.1007/s11102-015-0671-4)

85 Bando H, Iguchi G, Yamamoto M, Hidaka-Takeno R \& Takahashi Y. Anti-PIT-1 antibody syndrome; a novel clinical entity leading to hypopituitarism. Pediatric Endocrinology Reviews 201512 290-296.

86 Bando H, Iguchi G, Fukuoka H, Yamamoto M, Hidaka-Takeno R, Okimura Y, Matsumoto R, Suda K, Nishizawa H, Takahashi M et al. Involvement of PIT-1-reactive cytotoxic T lymphocytes in anti-PIT-1 antibody syndrome. Journal of Clinical Endocrinology and Metabolism 201499 E1744-E1749. (https://doi.org/10.1210/ jc.2014-1769)

87 Smith CJ, Bensing S, Burns C, Robinson PJ, Kasperlik-Zaluska AA, Scott RJ, Kämpe O \& Crock PA. Identification of TPIT and other novel autoantigens in lymphocytic hypophysitis: immunoscreening of a pituitary cDNA library and development of immunoprecipitation assays. European Journal of Endocrinology 2012166 391-398. (https:// doi.org/10.1530/EJE-11-1015)

88 Heaney AP, Sumerel B, Rajalingam R, Bergsneider M, Yong WH \& Liau LM. HLA markers DQ8 and DR53 are associated with lymphocytic hypophysitis and may aid in differential diagnosis. Journal of Clinical Endocrinology and Metabolism 2015100 4092-4097. (https://doi.org/10.1210/jc.2015-2702)

89 Lee J, Hyun SH, Kim S, Kim DK, Lee JK, Moon SH, Cho YS, Choe YS, Kim BT \& Lee KH. Utility of FDG PET/CT for differential diagnosis of patients clinically suspected of IgG4-related disease. Clinical Nuclear Medicine 201641 e237-e243. (https://doi.org/10.1097/ RLU.0000000000001153)

90 Sbardella E, Joseph RN, Jafar-Mohammadi B, Isidori AM, Cudlip S \& Grossman AB. Pituitary stalk thickening: the role of an innovative MRI imaging analysis which may assist in determining clinical management. European Journal of Endocrinology 2016175 255-263. (https://doi.org/10.1530/EJE-16-0455)

91 Fukuoka HHypohysitis. Endocrinology and Metabolism Clinics of North America 201544 143-149. (https://doi.org/10.1016/j.ecl.2014.10.011)
Received 6 January 2017

Revised version received 6 June 2018

Accepted 6 June 2018 